See Article page $\mathrm{XXX}$.

\section{Commentary: MAC attack}

\author{
Tsuyoshi Kaneko, MD, and Sary F. Aranki, MD
}

Mitral surgery with mitral annular calcification (MAC) is an ordeal for cardiac surgeons. Various techniques, including extensive or minimal decalcification, partial preservation of MAC, or extra-anatomical bypass, have been described, although the results have shown consistently high operative mortality. ${ }^{1}$ A report from the Society of Thoracic Surgeons Adult Cardiac Database study showed that the presence of MAC was associated with greater operative mortality with an odds ratio of $1.28 .^{2}$ In this edition of the Journal, Smith and his group ${ }^{3}$ reported a 2-institution series of transatrial balloon-expandable-valve (BEV) in MAC as a new approach for improved outcomes.

A total of 51 patients were treated with transatrial BEVin-MAC from 2015 to 2020. These were high-risk patients with a mean age of 73.9 years and a mean Society of Thoracic Surgeons score of $6.8 \%$. Nearly $75 \%$ were treated using a minimally invasive approach; $41.2 \%$ had concomitant septal myectomy with high technical success $(94.1 \%)$. The authors should be congratulated for their pioneering work in this field.

As the authors state in the discussion, transatrial BEVin-MAC can overcome the most significant limitations of the percutaneous transseptal approach, namely left ventricular outflow tract (LVOT) obstruction, by resecting the anterior leaflet and interventricular septum. The LAMPOON (laceration of the anterior mitral leaflet to prevent left ventricular outflow tract obstruction) technique or pre-emptive alcohol septal ablation may be used as an adjunct to the transseptal approach, although these are for advanced operators/centers and the risk of LVOT

\footnotetext{
From the Division of Thoracic and Cardiac Surgery, Brigham and Women's Hospital, Boston, Mass.

Disclosures: T.K. reported consultant for Edwards Lifesciences, Medtronic, and 4C Medical and speaker for Abbott. S.F.A. reported no conflicts of interest.

The Journal policy requires editors and reviewers to disclose conflicts of interest and to decline handling or reviewing manuscripts for which they may have a conflict of interest. The editors and reviewers of this article have no conflicts of interest.

Received for publication Sept 7, 2021; revisions received Sept 7, 2021; accepted for publication Sept 8, 2021.

Address for reprints: Sary F. Aranki, MD, Division of Thoracic and Cardiac Surgery, Brigham and Women's Hospital, 75 Francis St, Boston, MA 02115 (E-mail: saranki@partners.org).

J Thorac Cardiovasc Surg 2021; $\mathbf{\square}: 1-2$

$0022-5223 / \$ 36.00$

Copyright (c) 2021 Published by Elsevier Inc. on behalf of The American Association for Thoracic Surgery

https://doi.org/10.1016/j.jtcvs.2021.09.013
}

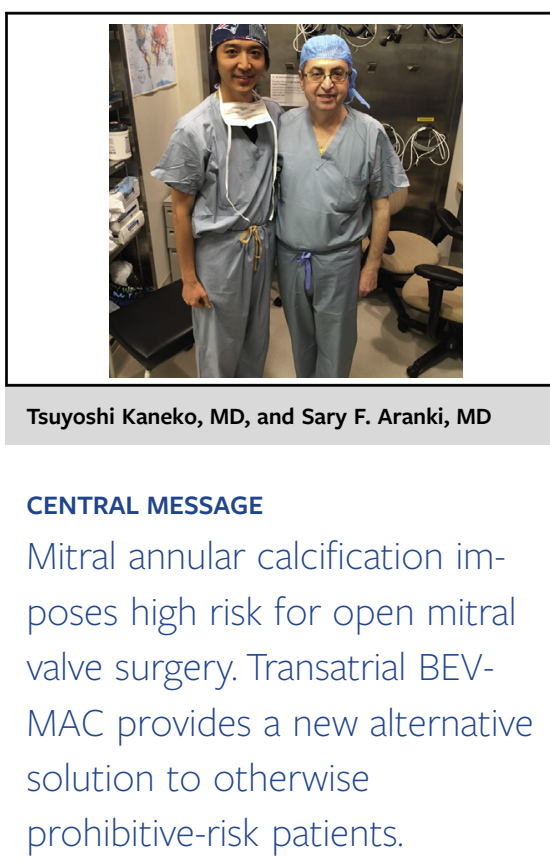

obstruction is not nullified. Furthermore, transatrial BEV-in-MAC allows treating large annulus or incomplete MAC with suture anchoring that cannot be treated with a transseptal approach.

In contrast, 30-day and 1-year mortality in this series remained relatively high $(13.7 \%, 33.3 \%$, respectively), although improving compared with the earlier series. Moreover, there was no improvement in the quality-of-life measures, and the capacity of 6-minute walk test diminished postoperatively. These results are partly due to the inherent risk of these patients with MAC and show the importance of careful patient selection. The patient must tolerate not only cardiopulmonary bypass but also be nonfrail to recover from the surgical invasiveness, and there must be continued effort to identify the right population to offer this surgery. In addition, the question of operator qualification exists, given the learning curve and the small number of cases. Should these procedures be accumulated to a center of excellence, or could the technique be disseminated to all cardiac surgeons?

New technology provides new solutions. Transatrial BEV-in-MAC provides an elegant solution using a true hybrid technique to what is known as a difficult problem. There are currently clinical trials enrolling patients with MAC for transapical/septal transcatheter mitral valve replacement devices, but the LVOT obstruction risk remains. With careful patient selection and technique, this procedure will continue to have a role and should be in the surgeon and heart team's armamentarium. 


\section{References}

1. Bedeir K, Kaneko T, Aranki S. Current and evolving strategies in the management of severe mitral annular calcification. J Thorac Cardiovasc Surg. 2019;157: 555-66.

2. Kaneko T, Hirji S, Percy E, Aranki S, McGurk S, Body S, et al. Characterizing risks associated with mitral annular calcification in mitral valve replacement. Ann Thorac Surg. 2019;108:1761-7.
3. Smith R, Hamandi M, Ailawadi G, George T, Mack M, DiMaio J, et al. Surgical implantation of balloon-expandable heart valves for the treatment of mitral annular calcification. J Thorac Cardiovasc Surg. August 25, 2021 [Epub ahead of print].

4. Praz F, Khalique OK, Lee R, Veeragandham R, Russell H, Guerrero M, et al. Transatrial implantation of a transcatheter heart valve for severe mitral annular calcification. J Thorac Cardiovasc Surg. 2018;156:132-42. 